\title{
VACTERL-H Association and Fanconi Anemia
}

\author{
B.P. Alter ${ }^{\mathrm{a}}$ P.S. Rosenberg ${ }^{\mathrm{b}}$ \\ ${ }^{a}$ Clinical Genetics Branch and ${ }^{b}$ Biostatistics Branch, Division of Cancer Epidemiology and Genetics, \\ National Cancer Institute, Rockville, Md., USA
}

\section{Key Words}

Birth defects • Fanconi anemia • VACTERL-H • VATER

\begin{abstract}
Patients with Fanconi anemia (FA) often have birth defects that suggest the diagnosis of VATER association. A review of 2,245 cases of FA reported in the literature from 1927 to 2012 identified 108 cases with at least 3 of the defining features of VATER association; only 29 had been so noted by the authors. The FA VATER signature was the significantly higher frequency of renal and limb (radial and/or thumb) anomalies (93\% of cases had both) compared with less than $30 \%$ of VATER patients; the presence of one or both of these birth defects should lead to testing for FA. The relative frequencies of the genotypes of the patients with FA VATER were strikingly different from those expected from the general FA population; only $19 \%$ were FANCA, while $21 \%$ were FANCB, $14 \%$ FANCD1/ $B R C A 2$, and $12 \%$ FANCD2. Consistent with their genotypes, those with the FA VATER phenotype had a worse prognosis than FA patients with milder phenotypes, with shorter median survival and earlier onset of malignancies. The early identification of FA patients among infants with VATER association should lead to earlier more proactive management, such as cancer surveillance and genetic counseling.
\end{abstract}

Copyright $\odot 2012$ S. Karger AG, Basel
VATER association, which has expanded to VACTERL, as well as VACTERL-H, includes a constellation of patients with any combination of 3 or more congenital anomalies described by the acronym (table 1) (MIM $192350,276950)$. VATER was first described in 1972. Subsequently, the frequency of the association in the general population was estimated to be 1 per 10,000 to 1 per 40,000 [Solomon et al., 2012], while the frequency in patients concurrently or subsequently diagnosed with Fanconi anemia (FA; MIM 227650) was stated to be 5\% [Esmer et al., 2004; Faivre et al., 2005]. FA is a primarily autosomal recessive syndrome (FANCB is X-linked recessive), with physical anomalies in about $60 \%$ of more than 2,200 patients reported in the literature, and high risks of bone marrow failure, acute myeloid leukemia (AML) and solid tumors, particularly head and neck squamous cell carcinomas and vulvar, vaginal and cervical squamous cell carcinomas [Shimamura and Alter, 2010]. One of the most severe FA genetic groups is composed of patients with biallelic mutations in FANCD1/BRCA2; in this group, we estimated the frequency of VATER to be $19 \%$ [Alter et al., 2007]. Those patients are at extremely high risk of early-onset mid-line brain tumors, Wilms tumors and AML. Since FA patients with the more severe phenotypes may be at the highest risk of early-onset bone marrow failure and AML [Faivre et al., 2000], early diagnosis

\section{KARGER}

Fax +4161306 1234

E-Mail karger@karger.ch

www.karger.com (c) 2012 S. Karger AG, Basel

1661-8769/13/0042-0087\$38.00/0

Accessible online at:

www.karger.com/msy
Blanche P. Alter

National Cancer Institute

6120 Executive Boulevard, EPS, Room 7020

Rockville, MD 20852 (USA)

E-Mail alterb@mail.nih.gov 


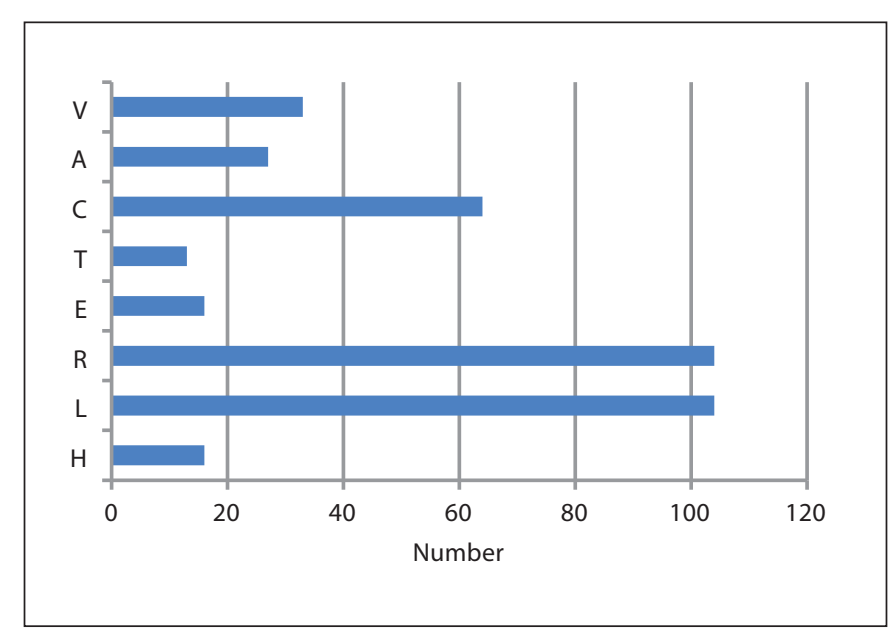

Fig. 1. Individual features of FA VATER. All patients had at least 3 of the VACTERL-H features. RL (renal and limb; radial ray) anomalies were the most frequent individual features, reported in 104 of the 108 patients with FA VATER.

Table 1. VACTERL-H

\begin{tabular}{ll}
\hline Feature & Definition \\
\hline $\mathrm{V}$ & vertebral anomalies \\
$\mathrm{A}$ & anal atresia \\
$\mathrm{C}$ & cardiac anomalies \\
$\mathrm{T}$ & tracheal-esophageal fistula \\
$\mathrm{E}^{*}$ & esophageal atresia, also duodenal atresia \\
$\mathrm{R}$ & renal structural anomalies \\
$\mathrm{L}$ & limb anomalies, essentially radii and/or thumbs \\
$\mathrm{H}$ & hydrocephalus \\
\hline
\end{tabular}

*Some studies include esophageal atresia with tracheal-esophageal fistula, while others score these anomalies separately, and still others include duodenal atresia with esophageal, as we have done.

prior to the development of those complications would result in earlier surveillance and treatment as well as genetic counseling for the parents.

We examined all published cases of FA $(n=2,245)$ to determine the frequency of VACTERL-H features, and we have identified a specific combination of anomalies which was present in almost all FA patients who met criteria for VATER association as well as combinations that were extremely rare in FA; these distinctive features may guide physicians toward or away from early FA testing. We have also examined associations of VACTERL-H anomalies with specific FA genotypes and compared the overall survival and cancer risks in FA VATER patients with other FA patients. The diagnosis of FA was accepted as stated by the authors of the literature articles and ranged from characteristic physical findings with and without hematologic problems to diagnoses based on increased chromosome breakage in peripheral blood lymphocytes cultured with DNA-crosslinkers, to identification of specific mutations in FA genes in the modern era.

\section{Materials and Methods}

Medline searches for relevant case reports have been performed frequently by BPA and include cases from 1927 through August 2012. The search terms were 'Fanconi' and 'VATER, VACTERL, or VACTERL-H'. Details in the case reports were entered in Microsoft Excel, and analyses were done with Excel 2010 (Microsoft, Redmond, Wash., USA), Stata 12.1 (StataCorp, College Station, Tex., USA), and Matlab 2008b software (The MathWorks, Natick, Mass., USA). The Kaplan-Meier product limit estimator was used to calculate actuarial survival probabilities by age and cumulative incidences in the absence of competing risks; subjects were censored at death and at stem cell transplant when appropriate [Kaplan and Meier, 1958]. The individual features of the VACTERL-H association were scored as single, double and multiple combinations. Comparisons were made between FA VATER with all FA cases identified as well as with a large series of VATER cases [Botto et al., 1997]. Statistical tests were 2 -sided, and p values $<0.05$ were considered significant.

\section{Results}

There were 2,245 cases of FA anemia reported in detail from 1927 to 2012; the male:female ratio was 1.1:1. Twenty-nine cases were called 'VATER' by the original authors. Although the physical findings were not described in many cases, an additional 79 cases, for a total of 108 of the 2,245 (88 of the 1,967 cases reported since 1972), listed congenital anomalies that were sufficient to qualify as VATER association (3 or more of the typical findings). The male:female ratio for the FA VATER subgroup was also 1.1:1. Table 1 describes the anomalies used in this study to characterize the VACTERL-H association; esophageal stenosis was scored separately from trachealesophageal fistula. One hundred and four of the $108 \mathrm{had}$ renal (R) and/or limb (L, radii and/or thumb) anomalies; 101 had both (fig. 1, 2). The next most frequent single finding was cardiac anomalies in 64 patients, of whom 61 had $\mathrm{R}$ and 60 had $\mathrm{L}$ abnormalities. For FA the most common combination of 3 VACTERL-H features was CRL, in 58 patients. Additional combinations seen in at least 10 


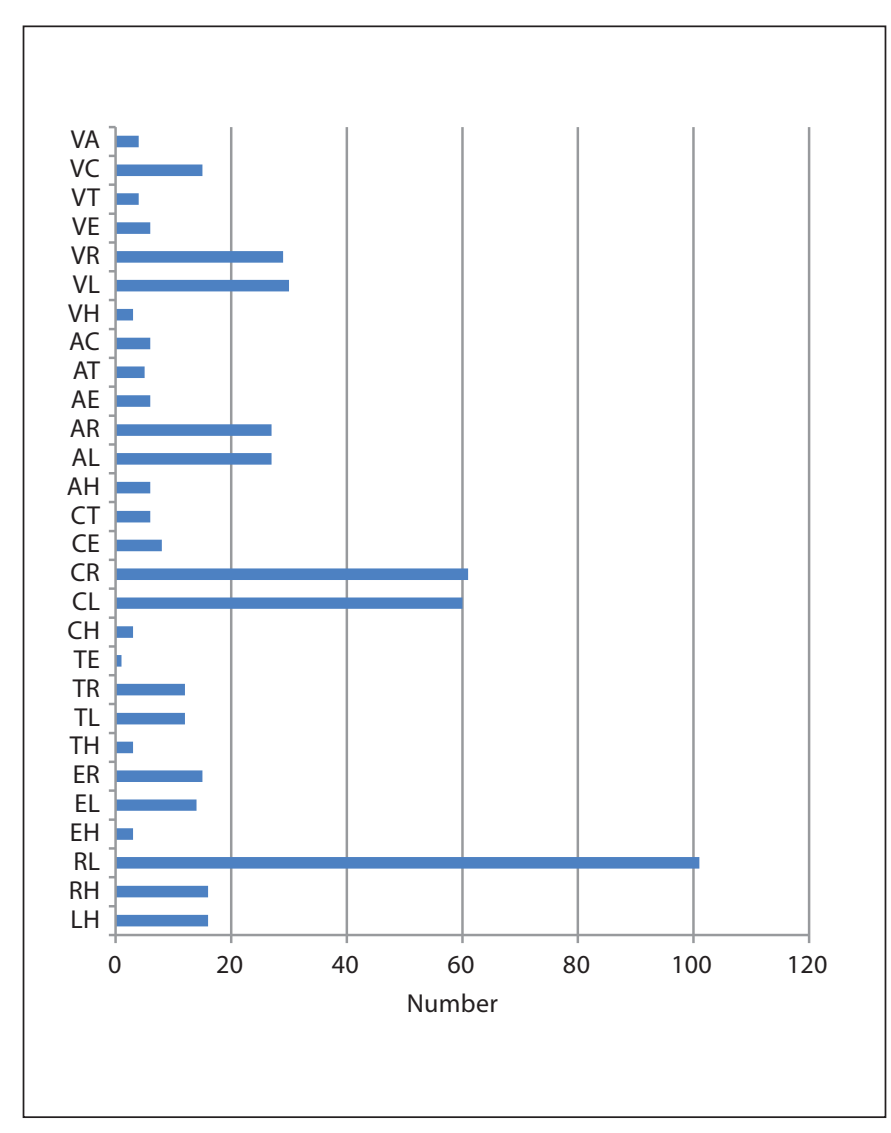

Fig. 2. Pairs of features of FA VATER. RL anomalies occurred together in 101 patients; the next most frequent pairs were cardiac and $\mathrm{R}$ or $\mathrm{L}$ anomalies (61 and 60 patients), followed by vertebral and $\mathrm{L}$ or $\mathrm{R}$ (24 and 25 patients).

patients included only VRL and ARL. Thus, in FA patients, VACTERL-H depends on the presence of RL anomalies, combined primarily with cardiac, anal or vertebral birth defects (fig. 3).

There are at least 15 genes involved in the FA/BRCA DNA repair pathway (http://www.rockefeller.edu/fanconi/), with mutations in FANCA, the most common at $65 \%$, followed by FANCC and FANCG at $10 \%$ each (fig. 4A). The genotypes of the FA VATER patients were available in 42 of the 108 cases. In this small subset, the relative frequencies of the genotypes of the patients with FA VATER were strikingly different from those expected from the general FA population (fig. 4B). Only $19 \%$ were FANCA, while $21 \%$ were FANCB, $14 \%$ FANCD1/BRCA2 and $12 \%$ FANCD2. Because of the small numbers, we combined the FA VATER genotypes according to their place in the DNA repair pathway. The core complex in-

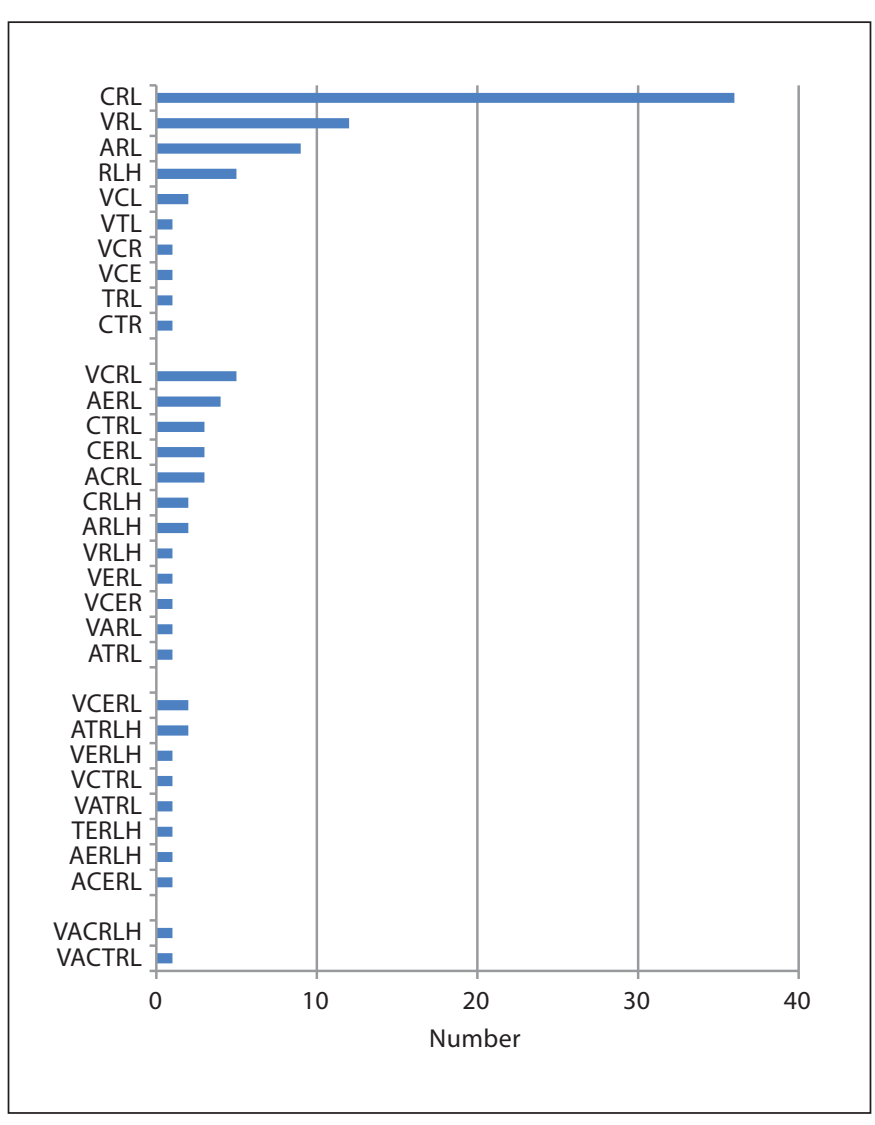

Fig. 3. Unique combinations of FA VATER features. The most frequent triplets were CRL in 36, and VRL and ARL in 12 and 9 patients, respectively. The most common combination of 4 features was VCRL in 5 patients. The identification of VACTERL-H in FA essentially included any combination in which $\mathrm{R}$ and $\mathrm{L}$ were found.

cludes proteins from FANCA, FANCB, FANCC, FANCE, FANCF, FANCG, FANCL, and FANCM and is required for monoubiquitination of proteins coded by FANCD2 and FANCI, which then lead to DNA repair by downstream proteins coded by FANCD1/BRCA2, FANCJ/ BRIP1/BACH2, FANCN/PALB2, FANCO/RAD51C, FANCP/SLX4, as well as BRCA1, and other products of genes that may be mutated in FA patients [Shimamura and Alter, 2010]. The pathway combination strategy demonstrated that $50 \%$ of the patients had mutations in 4 of the core complex genes (A, B, C, and G), 19\% in D2 or I and $31 \%$ in downstream genes (D1, J, N and O; fig. 4C). Despite the small numbers, these proportions are significantly different $(\mathrm{p}<0.001)$ from the expected values of $94 \%, 2 \%$ and $5 \%$, due to an excess of patients with mutations in the D2/I and downstream regions. The majority of the FA VATER mutations in the core complex were in 


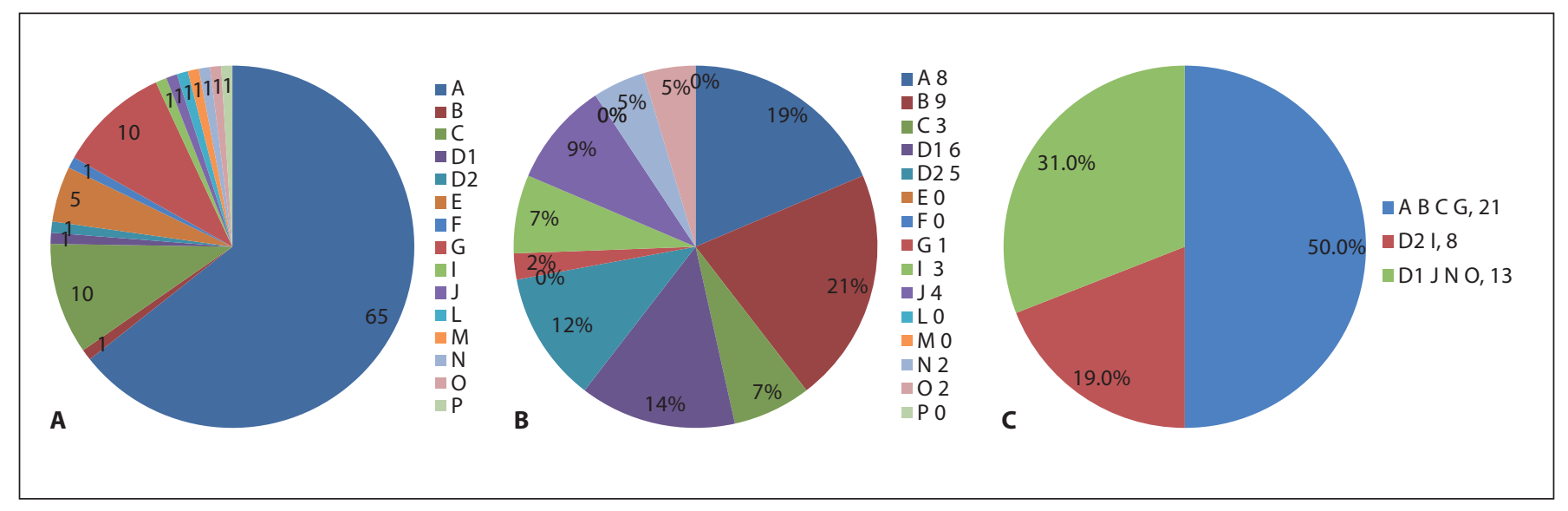

Fig. 4. Genotypes of FA and FA VATER patients. A All FA patients, adapted from published frequencies of FA genotypes (http:// www.rockefeller.edu/fanconi/). Group A comprises more than $65 \%$ of all patients. B Frequencies of FA genotypes reported in 42 of the 108 FA VATER patients. The most frequent groups were B, A, D1 and D2, followed by J, C, and I. C Frequencies of FA VATER genotypes according to their location in the FA/BRCA DNA repair pathway: the core complex $(\mathrm{A}, \mathrm{B}, \mathrm{C}, \mathrm{G} ; \mathrm{n}=21)$ was the largest group, followed by downstream genes (D1, J, N, O; $\mathrm{n}=13)$, and then the D1/I group $(n=8)$. FA VATER features appear to be distributed throughout the FA/BRCA DNA repair pathway.

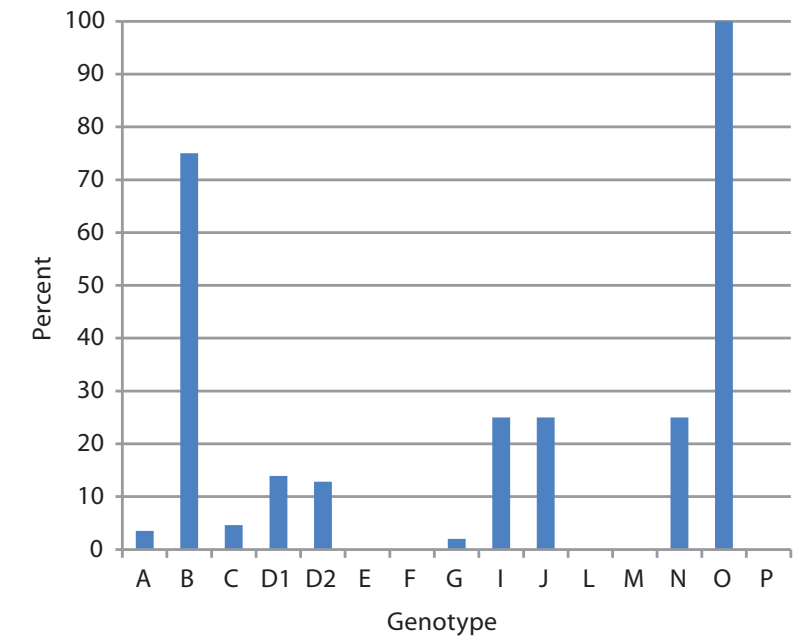

Fig. 5. Percent of all FA cases with genotype reported in the literature in which criteria were met for VATER association. The VATER features were more frequent than expected in $F A N C B, D 1$, $D 2, I, J, N$, and $O$, compared with an expected uniform distribution across genotypes.
FANCB, followed by FANCA. From another perspective, $75 \%$ of ( 9 of 12) patients reported in the literature to be FANCB had a VATER phenotype, in contrast with only $3.5 \%$ of the 227 FANCA patients identified in the literature review ( $\mathrm{p}=0.007$; fig. 5 ). The genotypes in which more than $20 \%$ of reported cases were FA VATER were primarily the rare types, including FANCB, FANCI, FANCJ, FANCN, and FANCO (only 2 patients were reported). However, the individual congenital anomalies were distributed in very similar patterns among the genotype groups, with $\mathrm{R}$ and $\mathrm{L}$ the most frequent, and either $\mathrm{C}$ or A the next most common (fig. 6).

Further exploration of the similarities or differences between FA VATER and the VATER association [Botto et al., 1997] identified distinct single birth defects which were significantly enriched in each group (fig. 7). The FA VATER patients had higher frequencies of anomalies of $\mathrm{R}, \mathrm{L}$ and $\mathrm{C}$, while the VATER group were more likely to have anomalies of $\mathrm{V}, \mathrm{A}$ and $\mathrm{T}(\mathrm{p}<0.001$ for each combination). The patterns of multiple anomalies also differed. Botto et al. [1997] identified 16 patterns among their 286 patients with VAR, ATR and VATR comprising more than half their cases (fig. 8), in contrast to the FA VATER group, in whom those combinations were found in less than $20 \%$ of cases. The most frequent combinations in FA VATER were CRL, ARL and VRL, which were found in more than half of the patients (fig. 3). Thus, the FA patients who met criteria for the VATER association ap- 


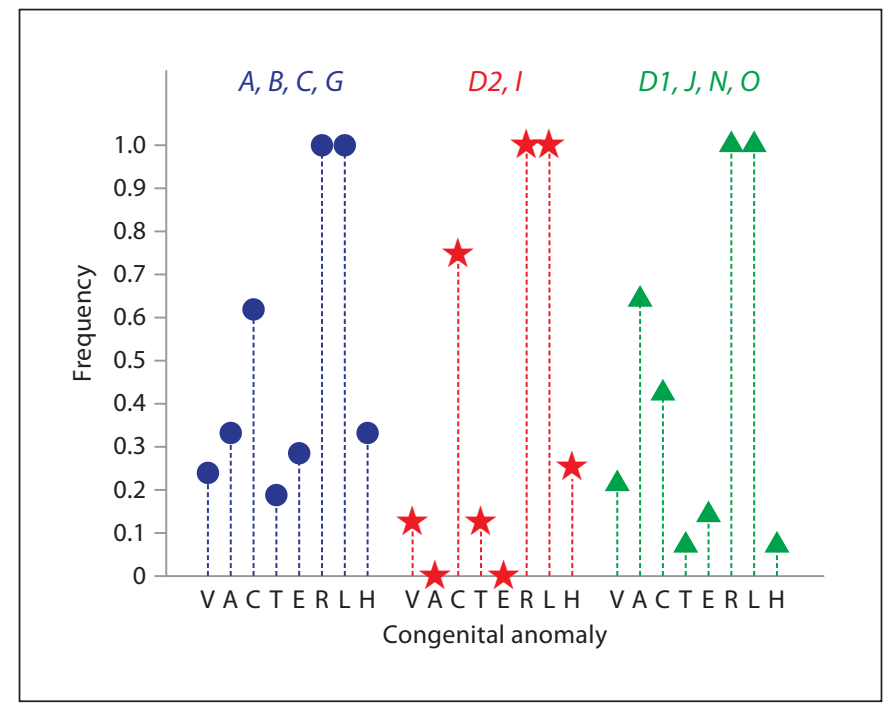

Fig. 6. Single features of VACTERL-H and FA pathway groups. The patterns of the single anomalies are very similar, and suggest that the pattern of the FA VATER association is not unique to a specific FA pathway location.

peared to have specific combinations of the requisite features that have not been reported for the general VATER population.

The subset of FA patients who could be called 'VATER' differed from other FA patients in their genotypes, discussed above, and also in their prognosis (which may in turn be related to their genotypes). They had a shorter survival (fig. 9), with a median of 14 years, compared with 25 years in the entire group of FA patients reported in the literature. The FA VATER patients also had earlier onset of cancer (fig. 10), with a cumulative incidence of $15 \%$ by age 10 years, compared with $9 \%$ in the entire FA case report series. The early cancers were brain, Wilms tumors and AML in 6 patients with FANCD1/ BRCA2, and one each FANCD2 and FANCN/PALB2. Thus the combination of a VATER phenotype, FA and a mutation in a downstream gene has a particularly bad prognosis.

\section{Discussion}

Although only $1 \%$ of the FA cases in the literature were originally identified as VATER association, $5 \%$ of the case reports overall $(108 / 2,245)$ and $5 \%(88 / 1,967)$ of the cases reported since VATER was first described include physi-

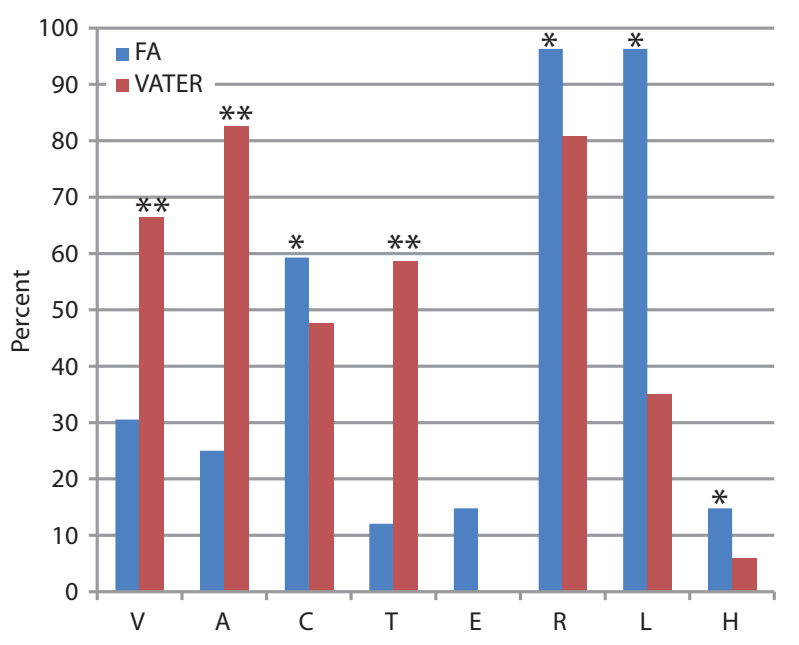

Fig. 7. Comparison of single features in 108 FA VATER with 286 VATER patients [Botto et al., 1997]. The features in higher percent in FA VATER than in VATER were $\mathrm{R}$ and $\mathrm{L}$, followed by $\mathrm{C}$ and $\mathrm{H}$, while those in higher percent in VATER without FA were V, A and T. ${ }^{*}$ Higher in FA VATER. ${ }^{* *}$ Higher in VATER.

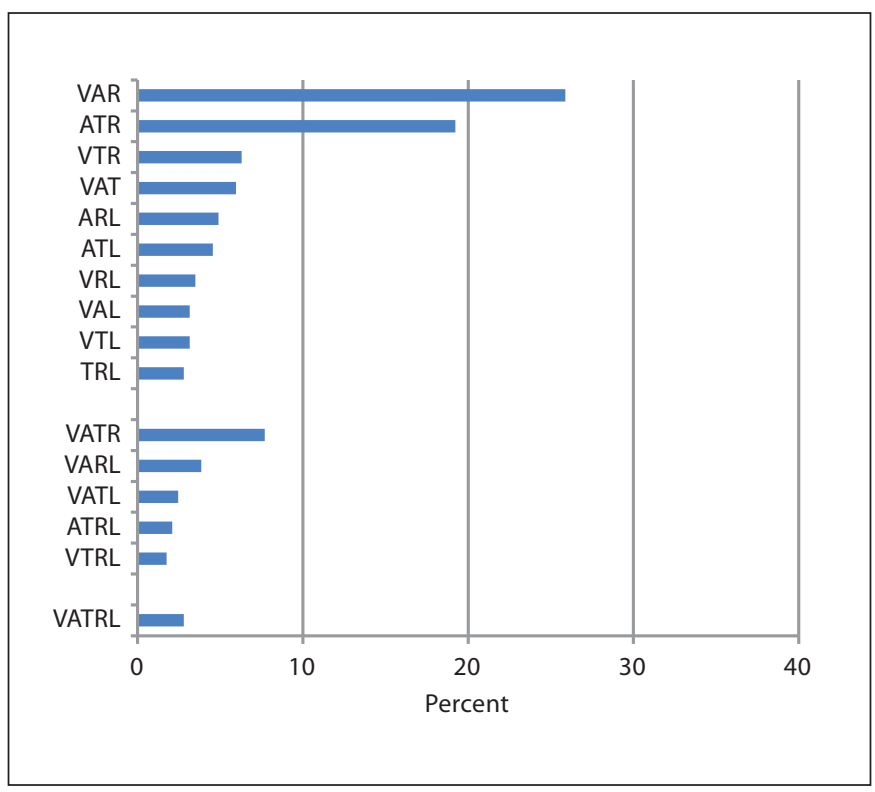

Fig. 8. Unique combinations of VATER features in the literature [Botto et al., 1997]. The most frequent were VAR in 26\%, ATR in $19 \%$ and VATR in $7 \%$. Both the VATER shown here and the FA VATER in figure 3 include combinations that are unique to each: CRL in FA VATER, and VAR and ATR in VATER. 
Fig. 9. Overall survival of FA VATER patients $(\mathbf{A})$ and all FA cases reported in the literature from 1927 to 2012 (B). The FA VATER group had a median survival of 14 years, compared with 25 years in the literature cases. Survival is by Kaplan-Meier method.

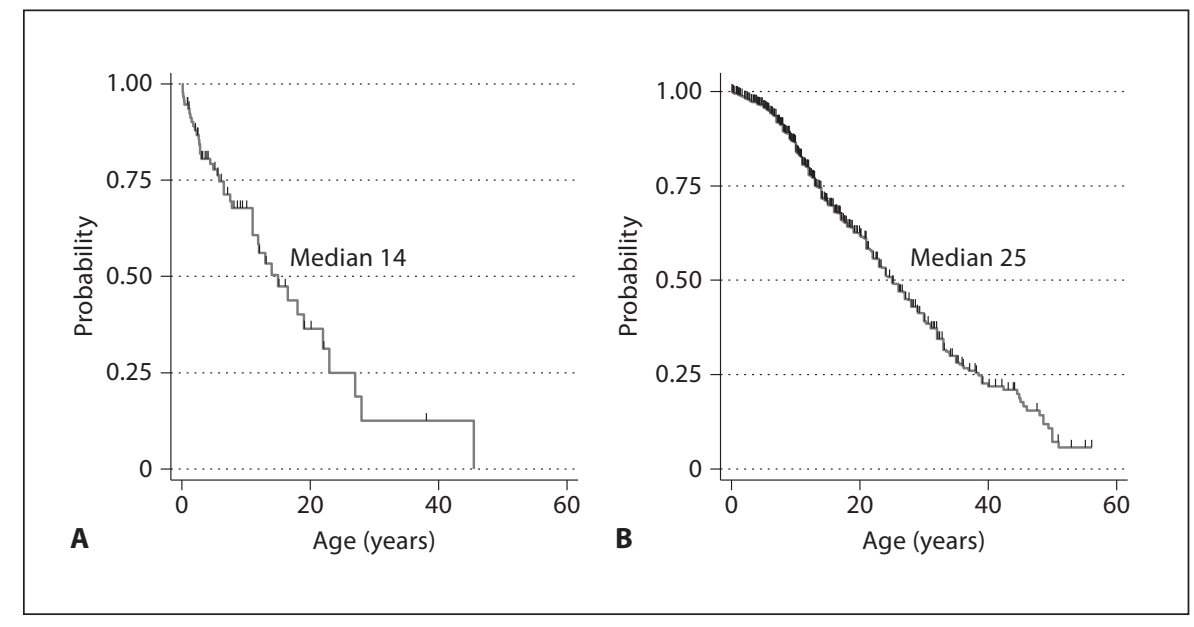

Fig. 10. Cumulative incidence of cancer calculated as 1 minus Kaplan-Meier curve with censoring at stem cell transplant or death. A FA VATER has a bolus of earlyonset cases ages 10 or younger, while in all FA (B) the accumulation is sigmoid, low in the early years, and approximating a linear incidence starting at around age 20. In FA VATER, the cumulative incidence of cancer was $15 \%$ by age 10 , while it was $9 \%$ by that age in the entire FA group.

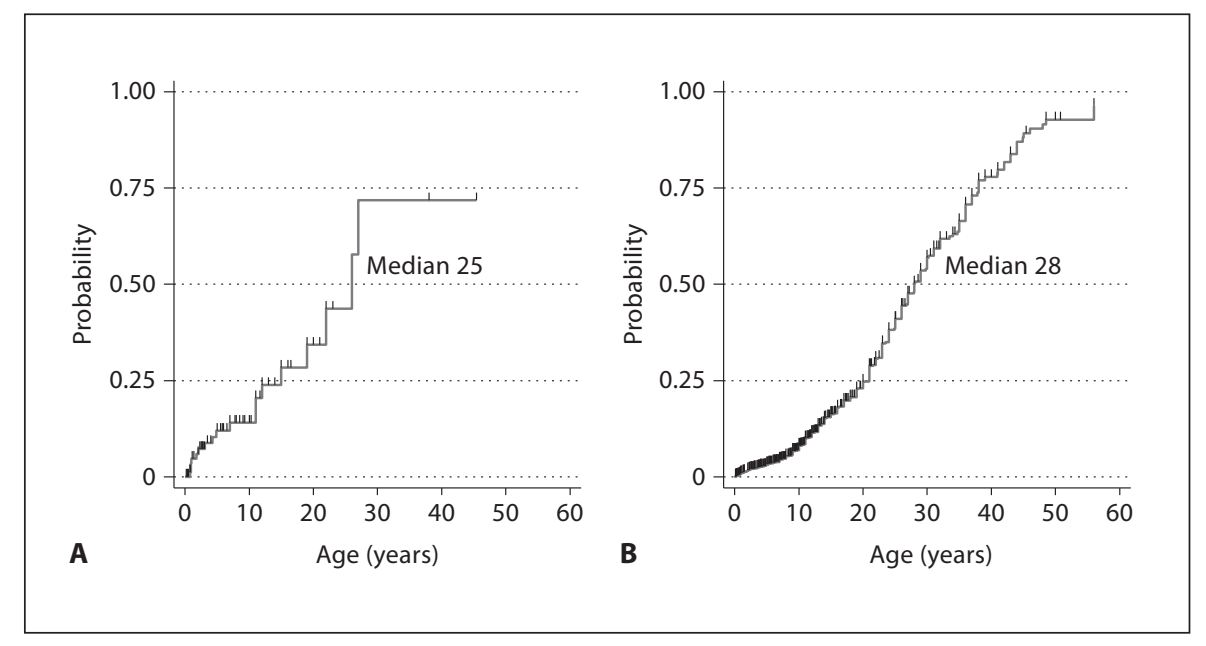

cal findings sufficient to indicate that they fit into the VATER association. This is broadly consistent with previous estimates [Esmer et al., 2004; Faivre et al., 2005] of the frequency of FA in VATER cohorts. However, since patient's appearances were not mentioned in $40 \%$ of the case reports, the frequency of VATER in FA could be closer to $10 \%$. A prospective study of all patients classified as VATER by geneticists and subsequently diagnosed with FA is necessary to determine the true frequency of FA in VATER; this requires that all VATER patients be screened for FA.

Half of the FANC genotypes with the VATER phenotype appear to be in the D2 ubiquitination and downstream pathways, and thus, a potential screening test might be the Western blot for D2 ubiquitination [Shimamura et al., 2002]. If this reaction does occur, then
FANCB, $A$ and $C$ need to be considered, since they comprise the other half of the patients. Lack of ubiquitination suggests that the patient has a form of FA associated with a particularly bad prognosis, with high risk of early-onset cancer and rapid demise. This conclusion supports the concept of genotype/phenotype/outcome correlation.

The combination of a careful physical examination with renal ultrasound, in which the FA pattern of VACTERL-H features is found, is more than sufficient to warrant FA testing with chromosome breakage, perhaps followed immediately with the Western blot for D2 ubiquitination. Gene sequencing can then be performed for the candidate genes suggested in this report. However, in those with downstream mutations, careful scrutiny for the types of cancers expected should begin without waiting for the gene sequencing result. 
This study suggests that FA patients within the VATER (or VACTERL-H) association can be immediately recognized by an 'FA VATER signal', the combination of RL (renal and radial ray) anomalies alone or with any other finding, which should lead to testing for FA. There should be no delay, waiting for bone marrow failure, AML or a tumor to lead to the diagnosis of FA. More than $90 \%$ of the FA VATER patients in the literature had both $\mathrm{R}$ and $\mathrm{L}$ anomalies, and more than $50 \%$ combined those findings with congenital cardiac disease, in contrast with none of the non-FA VATER patients.

There are several potential limitations to the data presented here. There may be a recognition bias among patients with birth defects in that FA testing may be triggered by the observation of abnormal radii and/or thumbs, alone or combined with hematologic or malignant disease. Identification of $\mathrm{R}$ anomalies requires a step beyond a physical examination, namely renal ultrasound, and thus, the diagnosis of FA may already have been entertained prior to finding the renal structural abnormalities. Another bias may have been due to reporting cases in which ultimately sufficient physical findings were identified, but they may not have been noted initially. It should be pointed out that the features of FA patients with VATER are not the age- and/or sun-exposure findings that are characteristic of FA, such as delayed growth and development, and café au lait spots and hyper- and hypopigmentation. Another limitation is that physical findings were not included in $40 \%$ of the literature case reports, and thus, the estimate of 5\% with VATER phenotype is indeed an estimate. Furthermore, the analysis relies on the accuracy of the diagnosis of FA in the cases reported, since the results of diagnostic FA testing by chromosome breakage were not always included (or even performed in the older cases), and on the accuracy of the descriptions of the birth defects. There are also limitations with regard to the 'control' VATER group [Botto et al., 1997], since there may have been some FA patients in that population, particularly since the birth defects were noted at birth, and the infants were not reclassified later if a specific diagnosis was identified.

A strength of this analysis is that it derives from careful annotation of all physical findings reported in more than 2,200 cases of FA in the literature and of genotypes in about 500 cases. The description of VATER features was diagnostic in 108 of 2,246; genotypes were recorded for 42 of the FA VATER and 500 FA overall. In both cases, the genotypes were reported more frequently in recent years when the genes had been identified. Despite the limitations discussed above, at least $5 \%$ of FA patients may be classified as VATER association, and it is incumbent to the geneticists who see these patients in infancy to consider the diagnosis of FA, and provide appropriate testing by chromosomal breakage, genetic counseling to the family and prompt referral to pediatric hematology/ oncology specialists.

\section{Acknowledgement}

This work was supported in part by the Intramural Research Program of the National Institutes of Health and the National Cancer Institute.

\section{References}

Alter BP, Rosenberg PS, Brody LC: Clinical and molecular features associated with biallelic mutations in FANCD1/BRCA2. J Med Genet 44:1-9 (2007).

- Botto LD, Khoury MJ, Mastroiacovo P, Castilla EE, Moore CA, et al: The spectrum of congenital anomalies of the VATER association: an international study. Am J Med Genet 71: 8-15 (1997).

-Esmer C, Sánchez S, Ramos S, Molina B, Frias S, Carnevale A: DEB test for Fanconi anemia detection in patients with atypical phenotypes. Am J Med Genet A 124A, 35-39 (2004).

\footnotetext{
Faivre L, Guardiola P, Lewis C, Dokal I, Ebell W, Kaplan EL, Meier P: Nonparametric estimation et al: Association of complementation group and mutation type with clinical outcome in Fanconi anemia. Blood 96:4064-4070 (2000). from incomplete observations. J Am Stat Assoc 53:457-481 (1958).

-Shimamura A, Alter BP: Pathophysiology and management of inherited bone marrow failure syndromes. Blood Rev 24:101-122 (2010).

aivre L, Portnoi MF, Pals G, Stoppa-Lyonnet D, le Merrer M, et al: Should chromosome breakage studies be performed in patients with VACTERL association? Am J Med Genet A 137:55-58 (2005).

-Shimamura A, Montes de Oca R, Svenson JL, Haining N, Moreau LA, et al: A novel diagnostic screen for defects in the Fanconi anemia pathway. Blood 100:4649-4654 (2002).

Solomon BD, Bear KA, Kimonis V, de Klein A, Scott DA, et al: Clinical geneticists' views of VACTERL/VATER association. Am J Med Genet Part A 2012, E-pub ahead of print.
} 